\title{
6-Gingerol inhibits hair cycle via induction of MMP2 and MMP9 expression
}

\author{
CHUN HOU ${ }^{1}$, YONG MIAO ${ }^{2}$, HANG JI ${ }^{1}$, SUSHENG WANG ${ }^{1}$, GANG \\ LIANG $^{1}$, ZHIHUA ZHANG $^{1}$ and WEIJIN HONG ${ }^{2}$ \\ ${ }^{1}$ Department of Plastic and Cosmetic Surgery, the First Affiliated Hospital of Guangzhou \\ Medical University, Guangzhou, 510120 Guangdong, P.R. China \\ ${ }^{2}$ Department of Plastic and Cosmetic Surgery, Nanfang Hospital, Southern Medical \\ University, Guangzhou, 510120 Guangdong, P.R. China
}

Manuscript received on May 16, 2017; accepted for publication on August 2, 2017

\begin{abstract}
6-Gingerol is the major active constituent of ginger. In the current study, we aimed to investigate the mechanisms underlying the effects of 6-Gingerol on hair growth. Mice were randomly divided into five groups; after hair depilation (day 0), mice were treated with saline, or different concentrations of 6-Gingerol for 11 days. The histomorphological characteristics of the growing hair follicles were examined after hematoxylin and eosin staining. The results indicated that 6-Gingerol significantly suppressed hair growth compared with that in the control group. And choose the concentration of 6-Gingerol at $1 \mathrm{mg} /$ $\mathrm{mL}$ to treated with mice. Moreover, 6-Gingerol $(1 \mathrm{mg} / \mathrm{mL})$ significantly reduced hair re-growth ratio, hair follicle number, and hair follicle length, which were associated with increased expression of MMP2 and MMP9. Furthermore, the growth factors, such as EGF, KGF, VEGF, IGF-1 and TGF- $\beta$ participate in the hair follicle cycle regulation and regulate hair growth. We then measured the concentrations of them using ELISA assays, and the results showed that 6-Gingerol decreased EGF, KGF, VEGF, and IGF-1 concentrations, and increased TGF- $\beta$ concentration. Thus, this study showed that 6 -Gingerol might act as a hair growth suppressive drug via induction of MMP2 and MMP9 expression, which could interfere with the hair cycle.
\end{abstract}

Key words: MMP2, MMP9, 6-Gingerol, hair growth.

\section{INTRODUCTION}

Hair loss, a common hair disorder resulting from dysregulation of the hair cycle, is characterized by a change in hair fiber production. Although hair loss is not life-threatening, image-distressing problems because of hair loss can affect the psychological wellbeing and normal lives of

Correspondence to: Chun Hou

E-mail: houchundoctor@sina.com patients (Trueb 2013). Because hair loss can critically affect the patients' social interaction, treatment options have become a central subject in orthopedic industry (Kiratipaiboon et al. 2016). However, most treatment modalities were proven ineffective owing to the complicated mechanisms involved in hair loss. Thus, exploration of novel effective agents to alleviate the symptoms of hair loss has drawn increasing attention in recent years. Emerging evidence has shown that compounds 
isolated from the traditional herbal medicines, such as green tea (Pazyar et al. 2012), the tuber fleece flower (Polygonum multiflorum Thunb.) (Fulwider et al. 2007, Park et al. 2012), and ginger (Zingiber officinale) (Pinski 2014), are capable of preventing hair loss and even promoting hair growth (Patel et al. 2015, Sampath et al. 2016).

Hair growth cycle is modulated by hair follicles, in which various growth factors, such as vascular endothelial growth factor (VEGF), insulin-like growth factor 1 (IGF-1), transforming growth factor- $\beta$ (TGF- $\beta$ ), epidermal growth factor (EGF), and keratinocyte growth factor (KGF/FGF7), are expressed (Bassino et al. 2015, Jung et al. 2015, Won et al. 2015). An increasing number of studies have found that hair follicle will produce paracrine signals that stimulate or inhibit the growth of follicular epithelium when it is stimulated. The paracrine signals contain VEGF and IGF-1 (Itami et al. 1995). Furthermore, studies also found that KGF can stimulate hair follicle growth, while EGF and TGF- $\beta$ can inhibit hair follicle growth (Fujie et al. 2001, Jindo et al. 1995, Philpott et al. 1994a, Shimaoka et al. 1995, Werner et al. 1994). Generally, hair growth cycle includes three defined stages: anagen (the active growth phase), catagen (the intermediate phase), and telogen (the resting phase) (Oh et al. 2016). During the three phases, the extracellular matrix (ECM) has been suggested to play a structural function (Bayer-Garner et al. 2002), which is related to the functions of the basement membrane components; type IV collagen (Brakebusch et al. 2000, Tamiolakis et al. 2001), laminin (Rudkouskaya et al. 2014), and other structural proteins. MMPs are a family of zincdependent proteases involved in the degradation and remodeling of the ECM (Pulkoski-Gross 2015). Among them, MMP2 (type IV collagenases) and MMP9 (type V collagenases) are universally secreted by several cell types during ECM remodeling (Li et al. 2002, Stamenkovic 2003). Regarding hair growth cycle, human hair follicles were shown to spontaneously secrete MMP2 and MMP9 in vitro. Additionally, hair follicle number and hair canal width decreased in MMP9-knockout mice, whereas increased activity of MMP9 contributed to hair bulb involution and remodeling both in vitro and in vivo. In addition, MMP2 has been shown to be involved in the hair cycle, and its expression is higher than that of MMP9; however, the exact role of MMP2 in hair growth cycle still needs further investigation (Miao et al. 2013a).

Thus, we aimed to investigate the effects of ginger extract on the activity of MMPs. 6-Gingerol, the major active constituent of ginger, has been shown to play an important role during hair cycle. However, the effects of 6-Gingerol on hair growth are complicated, given the recent findings that showed that 6-Gingerol could act as a potential hair growth suppressive drug, which opposes the promoting effects of ginger extract on hair growth. 6-Gingerol was shown to suppress human hair growth via its inhibitory and proapoptotic effects on human dermal papilla cells (DPCs), as well as prolongation of the telogen phase (Miao et al. 2013a).

Therefore, in the current study, we investigated the effects of 6-Gingerol on hair growth and hair follicle health. In addition, the molecular mechanisms underlying the effects of 6-Gingerol, particularly MMP signaling, were explored.

\section{MATERIALS AND METHODS}

\section{CHEMICALS}

Standard 6-Gingerol was purchased from Sigma (St. Louis, MO, USA). Other chemicals were commercially available, and were purchased as reagent-grade chemicals from Sinopharm (Shanghai, China).

\section{ANIMAL EXPERIMENTS}

Forty female C57BL/6 mice (8 weeks old) were purchased from the Experimental Animal Center 
of Southern Medical University (Guangzhou, China), and randomly divided into 5 groups ( $n=8$ / group). On day 0 , the telogen phase was induced by depilation of skin on the back of the C57BL/6 mice as previously described (Curtis et al. 2011). Briefly, hair was removed by topical application of calcium thioglycolate. Starting from the following day (day 1), $0.2 \mathrm{~mL}$ of different concentrations $(0.1,0.5,1$, and $2 \mathrm{mg} / \mathrm{mL})$ of 6-Gingerol in $75 \%(\mathrm{v} / \mathrm{v})$ ethanol was applied to the dorsal skin of each mouse twice daily for 10 days. The control mice received the vehicle alone. The back of each mouse was observed and photographed on day 11 after depilation. All mice were sacrificed on day 11 and, the histology of skin specimens isolated from the back of each mouse was examined after hematoxylin and eosin (H\&E) staining. All experimental procedures were carried out in accordance with the guidelines of the National Institute of Health Guide for the Care and Use of Laboratory Animals, and were approved by the Experimental Animal Ethical Committee of Southern Medical University (no: L2016029).

\section{HAIR RE-GROWTH EVALUATION}

Hair re-growth was evaluated routinely. Briefly, photographs of the mice were regularly taken during each evaluation. Then, hair re-growth was evaluated by image analysis according to the following formula: \% hair re-growth = hairy (black) area/hair removal area (1).

\section{HISTOLOGICAL ANALYSIS}

After mice were euthanized, the skin tissues were collected. They were fixed in $10 \%$ neutral buffered formalin for $24 \mathrm{~h}$, dehydrated with increasing concentrations of ethanol (70-100\%), and embedded in paraffin wax. Then, sections of $5-\mu \mathrm{m}$ thickness were prepared. In the H\&E-stained skin sections, growing hair follicles were scored based on the accepted morphological guidelines, and the length of the hair follicles was measured using Image $\mathrm{J}$ software.

\section{REAL-TIME POLYMERASE CHAIN REACTION (RT- PCR)}

Total RNA was extracted from the skin samples with TRIzol (Thermo Fisher Scientific, Waltham, MA, USA). Then, DNase I was used to remove genomic DNA. RNA (200 ng) of each mouse was reverse transcribed into complementary DNA. Then, RT-PCR was performed to measure the mRNA expression levels of MMP2, MMP9, and glyceraldehyde-3-phosphate dehydrogenase (GAPDH). Thermal cycles were as follows: 10 min at $95{ }^{\circ} \mathrm{C}$ for enzyme activation, denaturation for $15 \mathrm{~s}$ at $95{ }^{\circ} \mathrm{C}$, annealing for $60 \mathrm{~s}$ at $60{ }^{\circ} \mathrm{C}$, and extension for $60 \mathrm{~s}$ at $72{ }^{\circ} \mathrm{C}$. RT-PCR was performed for at least 30 cycles. A dissociation curve was generated to assure the absence of nonspecific products or primer dimers. Relative quantification was conducted using the $\Delta \Delta \mathrm{C}_{\mathrm{T}}$ method. The expression levels of the genes of interest were normalized to that of GAPDH. The specific primers were MMP2 (amplicon size: 176 bp): 5'-CGA TGT CGC CCC TAA AAC AG-3' (forward), 5'-GCA TGG TCT CGA TGG TGT TC-3' (reverse); the specific primers were MMP9 (amplicon size: 190 bp): 5'-AAA ACC TCC AAC CTC ACG GA-3' (forward), 5'-GTG GTG TTC GAA TGG CCT TT3' (reverse).

\section{WESTERN BLOTTING ASSAY}

Total protein in different groups was extracted using a total protein extraction kit, according to the manufacturer's instructions (Wanleibio, China). GAPDH was employed as an internal reference protein. After determination of protein concentrations using the bicinchoninic acid (BCA) method, $40 \mu \mathrm{g}$ of the protein sample was subjected to $10 \%$ sodium dodecyl sulfate-polyacrylamide gel electrophoresis (SDS-PAGE). Then, the proteins were transferred onto polyvinylidene difluoride 
(PVDF) membranes, washed with TTBS for $5 \mathrm{~min}$, and then incubated with skimmed milk powder solution for $1 \mathrm{~h}$. Primary antibodies against MMP2, MMP9, and GAPDH were incubated with the membranes $4{ }^{\circ} \mathrm{C}$ overnight. After washing with TTBS four times, secondary horseradish peroxidase (HRP)-conjugated IgG antibodies were added to the membranes and incubated for $45 \mathrm{~min}$ at $37^{\circ} \mathrm{C}$. After washing with TTBS for six times, the blots were developed using Beyo enhanced chemiluminescence (ECL) Plus reagent, and the results were recorded using Gel imaging system. The primary antibodies were anti-GAPDH antibody (Dilution 1:2000; Abcam, ab8245, molecular weight $37 \mathrm{kDa}$ ), anti-MMP2 antibody (Dilution 1:1000; Abcam, ab24331), anti-MMP9 antibody (Dilution 1:1000; Abcam, ab38898, molecular weight $92 \mathrm{kDa}$ ).

\section{ZYMOGRAPHY ASSAY}

Activities of MMP2 and MMP9 were detected by zymography assays according to the manufacturer's instructions (Millipore). Cell culture supernants were separated in a $10 \%$ polyacrylamide gel containing $1 \mathrm{mg} / \mathrm{mL}$ gelatin. Gels were washed with $2.5 \%$ Triton $\mathrm{X}-100$ for 30 mins, followed by washing once with reaction buff to remove the SDS, incubated overnight at $37{ }^{\circ} \mathrm{C}$. Next day, the gels were stained with $0.5 \%$ coomassie Blue R-250 (Sigma) for $1 \mathrm{~h}$ and de-stained with an appropriate coomassie R-250 de-staining solution.

\section{ENZYME-LINKED IMMUNOSORBENT ASSAY} (ELISA) ASSAY

The expression levels of EGF, KGF, VEGF, IGF-1, and TGF- $\beta$ in culture medium was measured; $500 \mu \mathrm{l}$ culture supernatant was harvested from the cultured cells. The activities of EGF, KGF, VEGF, IGF-1, and TGF- $\beta$ in the culture medium were detected using the ELISA kit (R\&D Systems, Minneapolis, MN, USA) following manufacturer's instructions. A 96-well plate was coated with monoclonal
anti-EGF, anti-KGF, anti-VEGF, anti-IGF-1, and anti-TGF- $\beta$, and then was detected by secondary antibody conjugated to horseradish peroxidase. The absorbance was determined at $450 \mathrm{~nm}$ using a microtiter reader (Multiskan Go microplate reader, Thermo Scientific, Italy).

\section{STATISTICAL ANALYSIS}

All data were expressed as the means \pm standard deviations (SD) of three independent experiments. All statistical analyses were conducted using SPSS 13.0 (19.0 IBM Corporation, Armonk, NY, USA). Differences among experimental groups were evaluated by student's $t$-test. Analysis of variance was used for pairwise comparisons. $P<0.05$ was considered statistically significant.

\section{RESULTS}

ADMINISTRATION OF 6-GINGEROL DELAYED THE TRANSITION FROM TELOGEN TO ANAGEN in vivo

When the dorsal pelage hair follicles were in the telogen phase, the backs of mice were shaved, and those showing a uniform telogen stage skin were selected. The dorsal skin was treated with the vehicle alone (control), or with 6-Gingerol at different concentrations twice daily for 10 days. As shown in Figure 1a, the hair of mice in the control group re-grew to the original status, whereas 6-Gingerol treatment for 10 days after depilation inhibited hair re-growth in a dose-dependent manner. Based on the statistical analysis of the results (Fig. 1b), application of 1 and $2 \mathrm{mg} / \mathrm{mL}$ 6-Gingerol had the strongest inhibitory effects on hair re-growth, compared with that in the other groups $(P<0.05)$. These results were further validated by observation of the morphological features of hair follicles in different groups. Topical application of 6-Gingerol significantly and dose-dependently decreased the number of hair follicles (Fig. 2). On day 11 after depilation, hair re-grew to the original status in the normal control mice, whereas obvious faint hair 
a

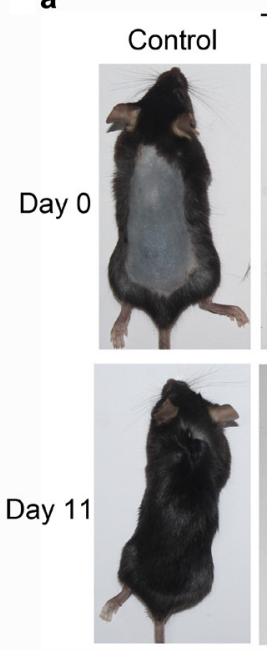

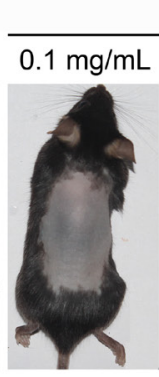

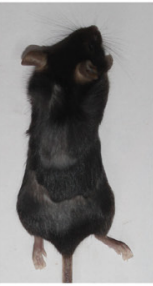

6-Gingerol
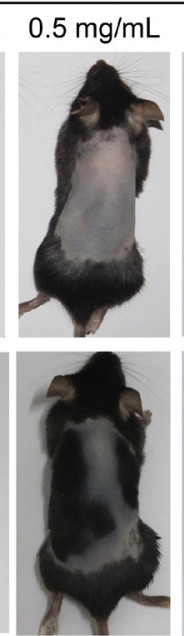
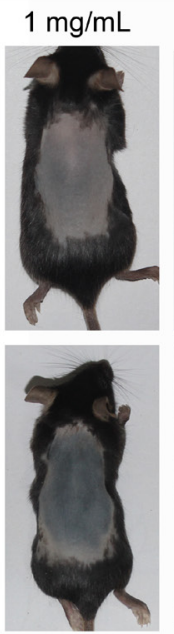

\section{$2 \mathrm{mg} / \mathrm{mL}$}
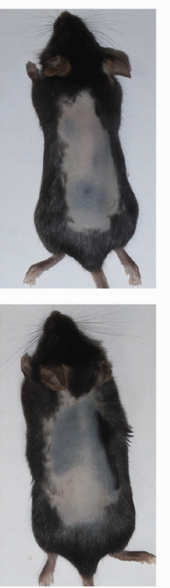

b

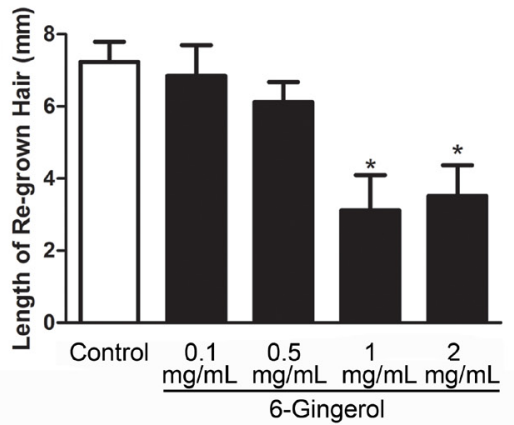

Figure 1 - Administration of 6-Gingerol inhibited the transition from telogen to anagen in C57BL/6 mice. After depilation, the skin on the back was treated with the vehicle (right), or 6-Gingerol (left) at different concentrations $(0.1,0.5,1$, and $2 \mathrm{mg} / \mathrm{mL}$ ) twice daily for 10 days. Photographs of each animal were taken on day 11. Compared to the vehicle-treated control mice, 6-Gingerol dose-dependently inhibited anagen induction. (a) Day 0 and day 11 after depilation; (b) length of re-grown hair was evaluated in all groups. All experiments were independently repeated three times. $* P<0.05$ versus the control group.

Control (day 0)

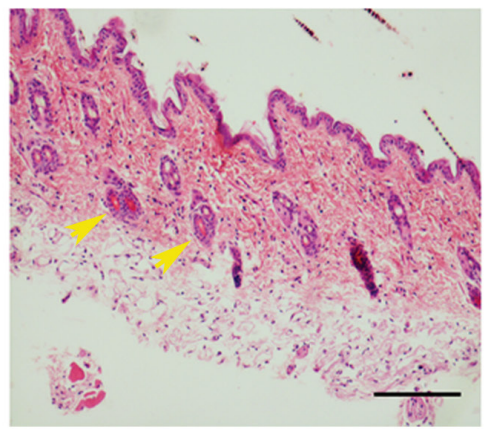

$0.5 \mathrm{mg} / \mathrm{ml}$ 6-Gingerol (day 11)

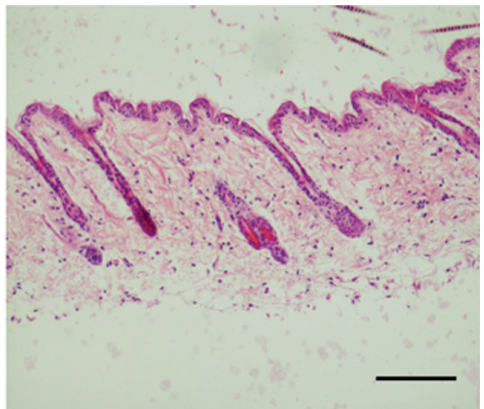

Control (day 11)

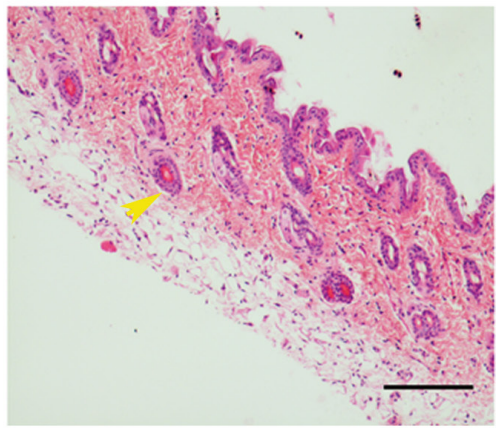

$1 \mathrm{mg} / \mathrm{ml}$ 6-Gingerol (day 11)

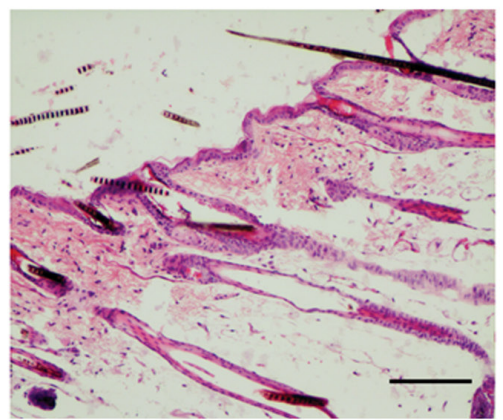

\section{$0.1 \mathrm{mg} / \mathrm{ml}$ 6-Gingerol (day 11)}

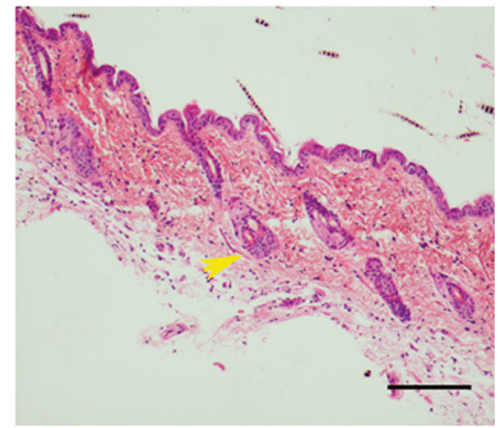

$2 \mathrm{mg} / \mathrm{ml}$ 6-Gingerol (day 11)

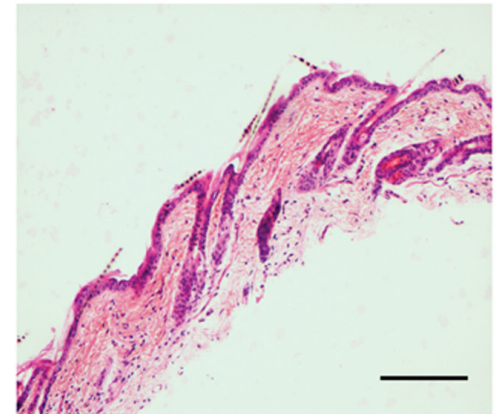

Figure 2 - 6-Gingerol decreased the number of hair follicles in C57/BL6 mice. The effects of 6-Gingerol on the hair follicles were assessed with H\&E staining on day 11 after depilation. The yellow arrows indicate the new hair follicle. Each scale bar represents $100 \mu \mathrm{m}$. 
re-growth was observed after topical application of 1 and $2 \mathrm{mg} / \mathrm{mL}$ 6-Gingerol. Based on the results of the hair re-growth assay, which showed that $1 \mathrm{mg} / \mathrm{mL}$ 6-Gingerol exhibited the strongest inhibitory effects, this concentration was used in the subsequent assays. And the number of follicle was less in 6-Gingerol group than the control group. It indicated that 6-Gingerol reduced the follicle generation.

\section{ADMINISTRATION OF 6-GINGEROL NOT ONLY}

DECREASED HAIR FOLLICLE NUMBER BUT ALSO

REDUCED THE LENGTH OF HAIR FOLLICLES in vivo

As shown in Figure 3a, the hair re-growth ratio in mice treated with $1 \mathrm{mg} / \mathrm{mL}$ 6-Gingerol was significantly lower than that in the control group $(P$
$<0.05)$. The number of hair follicles also decreased in mice treated with $1 \mathrm{mg} / \mathrm{mL}$ 6-Gingerol (Fig. 3b). Moreover, administration of 6-Gingerol not only decreased hair follicle number but also restricted the length of hair follicles in mice (Fig. 3c), which confirmed the inhibitory effects of 6-Gingerol on hair growth cycle.

\section{ADMINISTRATION OF 6-GINGEROL INDUCED THE EXPRESSION OF MMP2/MMP9 DURING HAIR CYCLE in vivo}

The activities of MMP2 and MMP9 fluctuated during the hair cycle, with a peak at the early anagen phase and then decreased during the catagen to telogen phases. In this study, the mRNA expression of MMP2 and MMP9 in the hair a

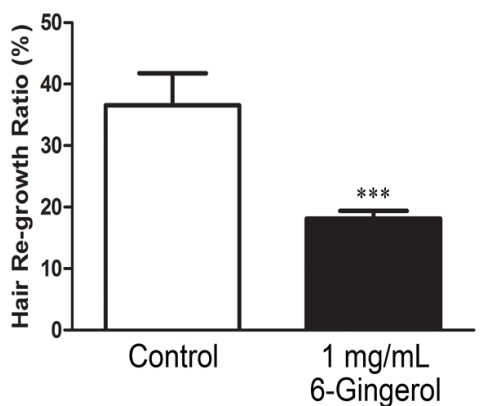

b

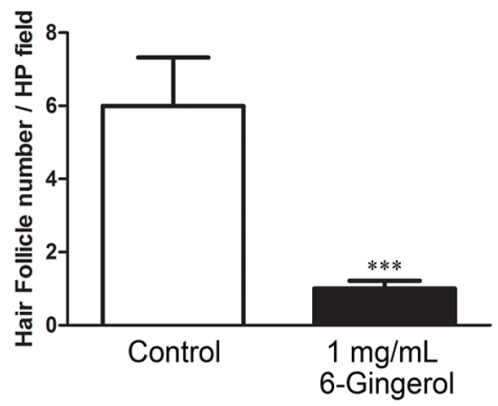

C

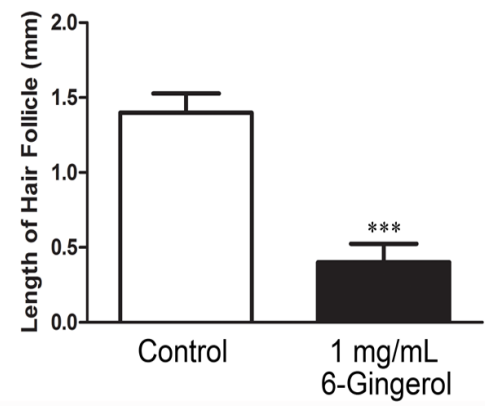

Figure 3 - Administration of 6-Gingerol not only decreased hair follicle number but also restricted the length of hair follicles in vivo. (a) Hair re-growth ratio determined on day 11 after depilation; (b) number of hair follicles evaluated on day 11 after depilation; (c) length of hair follicles measured on day 11 after depilation. $* * * P<0.001$ versus the control group.
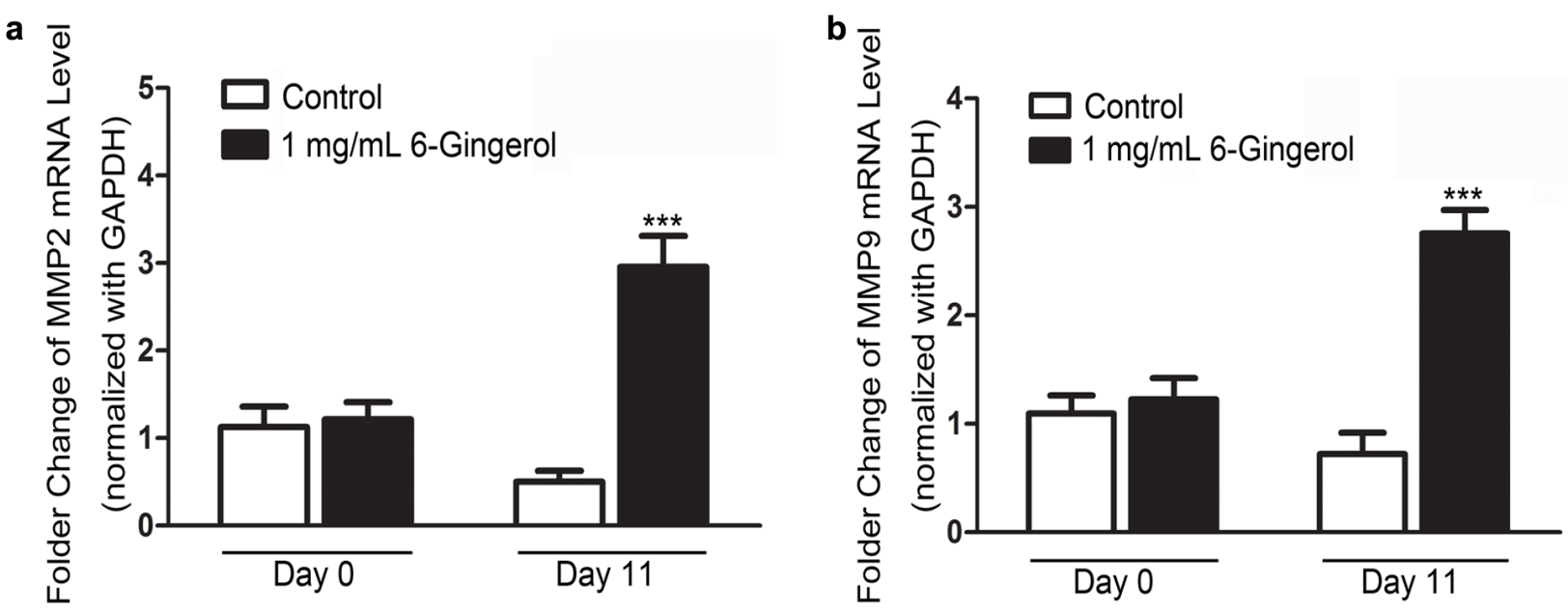

Figure 4 - Administration of 6-Gingerol induced MMP2 and MMP9 mRNA expression. (a) Quantitative analysis results of RTPCR validation of MMP2; (b) quantitative analysis results of RT-PCR validation of MMP9. All experiments were independently repeated three times. $* * * P<0.001$ versus the control group. 
follicles was examined on day 11 after depilation. Figure 4 shows that the mRNA levels of MMP2/ MMP9 increased after treatment with $1 \mathrm{mg} / \mathrm{mL}$ 6-Gingerol on day 11 after depilation. In addition, similar changing patterns were observed for MMP2 and MMP9 at the protein level, which confirmed the induction of MMPs by Gingerol (Fig. 5a and 5b). Furthermore, MMP2 and MMP9 activities in cell culture supernatants were measured by zymography assays, and the results indicated that the activities of MMP2 and MMP9 were increased after treatment with $1 \mathrm{mg} / \mathrm{mL}$ 6-Gingerol on day 11 after depilation (Fig. 5c and 5d).

\section{ADMINISTRATION OF 6-GINGEROL DECREASED EGF, KGF, VEGF, AND IGF-1 CONCENTRATIONS, AND INCREASED TGF-B CONCENTRATION}

In addition, we further detected the concentrations of EGF, KGF, VEGF, IGF-1, and TGF- $\beta$ using ELISA assays, and found that 6-Gingerol decreased

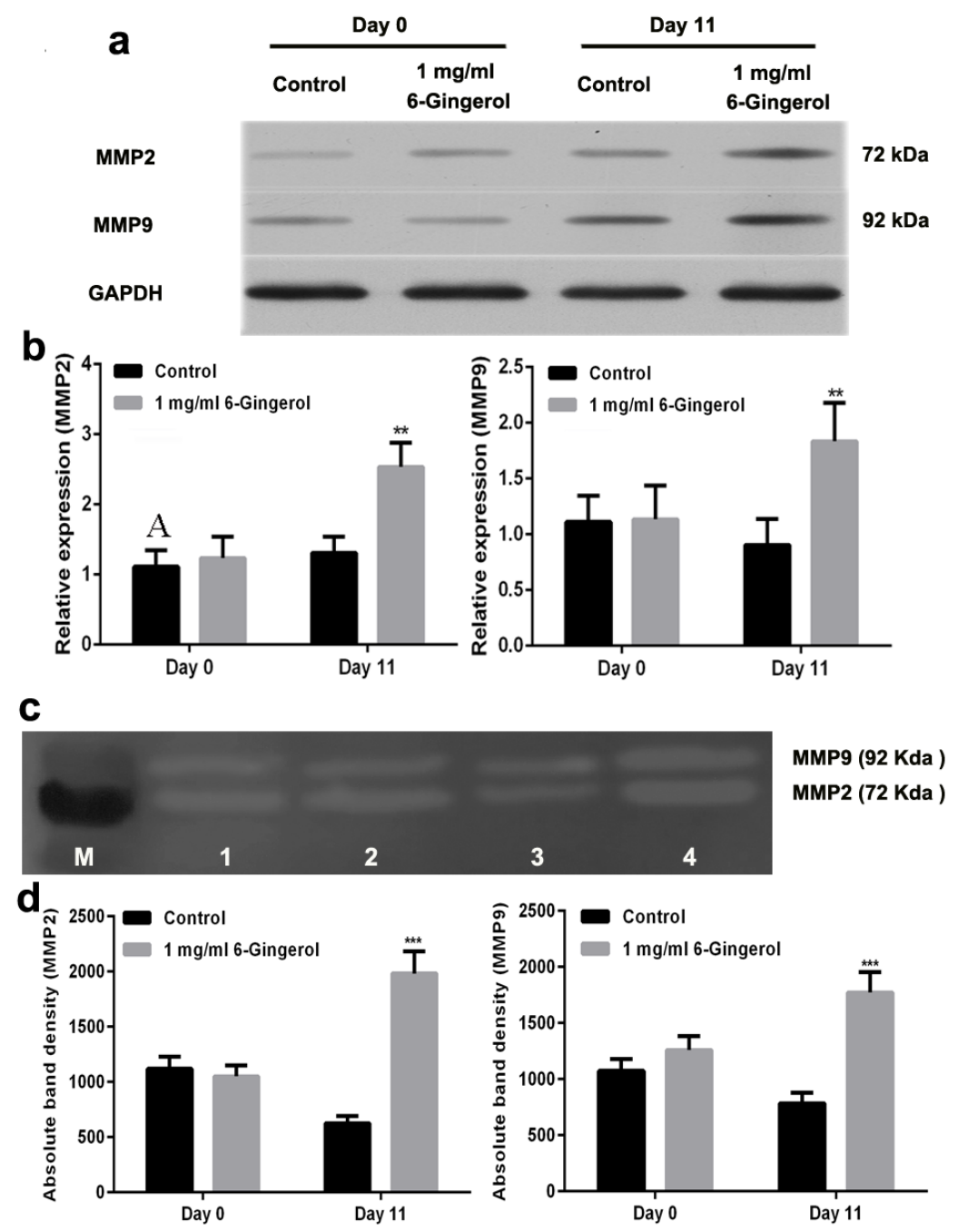

Figure 5 - Administration of 6-Gingerol induced MMP2 and MMP9 protein expression. (a) Representative images of the western blotting assay; (b) quantitative analysis results of western blotting assay of MMP2; (c) MMP2 and MMP9 activities in cell culture supernatants were measured by zymography assays. (d) quantitative analysis results of of MMP2 and MMP9. All experiments were independently repeated three times. ${ }^{* *} P<0.01$ and $* * * P<0.001$ versus the control group. 

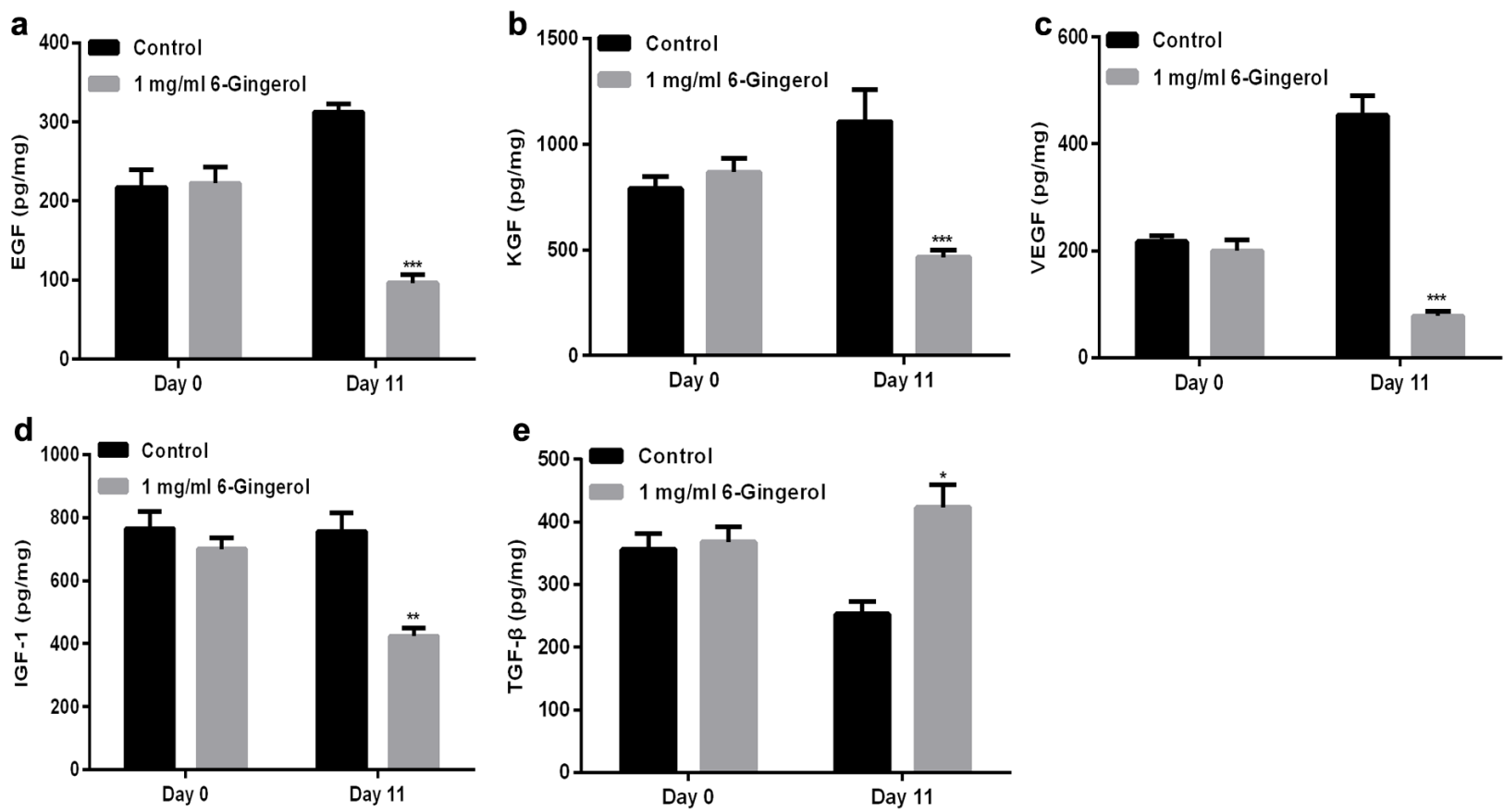

Figure 6 -Administration of 6-Gingerol decreased EGF, KGF, VEGF, and IGF-1 concentrations, and increased TGF- $\beta$ concentration. (a) EGF concentration was detected by ELISA assay, (b) KGF concentration was detected by ELISA assay, (c) VEGF concentration was detected by ELISA assay, (d) IGF-1 concentration was detected by ELISA assay, (e) TGF- $\beta$ concentration was detected by ELISA assay. All experiments were independently repeated three times. $* P<0.05$, $* * P<0.01$ or $* * * P<0.001$ versus the control group.

EGF (Fig. 6a), KGF (Fig. 6b), VEGF (Fig. 6c), and IGF-1 (Fig. 6d) concentrations, and increased TGF- $\beta$ concentration (Fig. 6e).

\section{DISCUSSION}

Ginger (Z. officinale) is a traditional herb that has been used in East Asia for prevention of hair loss for centuries (Zhu et al. 2015). However, little evidence has been found to support the claimed effects of ginger on hair growth. On the contrary, scientists have recently inferred that 6-Gingerol, the main active component of ginger, has the potential to inhibit hair growth in vitro and in vivo (Chakraborty et al. 2012, Miao et al. 2013b). To verify this theory, we investigated the effects of 6-Gingerol on hair growth and the related mechanisms. Our results showed that 6-Gingerol suppressed hair growth via induction of MMP2 and MMP9 mRNA and protein expression, which supported the findings that ginger extract could impair the hair growth cycle, rather than protecting the hair follicles.

6-Gingerol has been shown to induce apoptosis, mainly through stimulation of the mitochondrial death pathway, which is primarily regulated by Bcl-2 family proteins, particularly the proapoptotic Bax and antiapoptotic Bcl-2 proteins (Hou et al. 2015). Contrary to the potential protective effects of ginger on hair loss, 6-Gingerol was proven to suppress human hair growth via its proapoptotic effects on DPCs in vitro, as well as prolongation of the telogen phase in vivo. In addition, our results showed that the inhibitory effects of 6-Gingerol on hair growth might be attributed to its effects on ECM production in the hair growth cycle.

Hair grows in cycles of various phases: anagen is the growth phase; catagen is the involuting or regressing phase; and telogen, the 
resting or quiescent phase. Each phase has several morphologically and histologically distinguishable sub-phases (Geyfman et al. 2015, Plikus et al. 2014). In anagen phase, the cells in the papilla divide to produce new hair fibers, and the follicle buries itself into the dermal layer of the skin to nourish the strand. In catagen phase, the follicular melanocytes cause apoptosis. The hair follicle shrinks due to disintegration and the papilla detaches and "rests," cutting the hair strand off from its nourishing blood supply. Finally, the length of the terminal fibers increases when the follicle pushes them upward. In telogen phase, the epidermal cells continue to grow in the hair follicle without taxing the body's resources (Choi et al. 2011, Grinzi 2011, Harkey 1993). At some point, the follicle will begin to grow again, softening the anchor point of the shaft initially. The hair base will break free from the root and the hair will be shed. The new hair shaft will begin to emerge once the telogen phase is complete. The process results in normal hair loss known as shedding (Lay et al. 2016). Under normal depilation treatment, hair will enter the growing period and appear be a lot of new nipple. In our study, all mouse hair follicles have changed, and produced new hair follicles after dehairing. But the production of new hair follicles and the growth of hair were inhibited after 6-Gingerol treatment. Therefore, we suggested that 6-Gingerol can suppress hair shaft elongation and a possible mechanism of inhibiting the growth of hair is by increasing MMP-2 and MMP-9 expressions.

The morphological and physiological functions of the hair follicles are regulated by the ECM, where its degradation and remodeling is necessary for hair cycle progression and hair follicle development (Chen et al. 2015). A large number of studies have shown that matrix metalloproteinases (MMPs) as a kind of zinc-dependent enzymes, exerts an important function in regulating the degradation of most of the ECM and basement membrane components, and in causing the attenuation of the organizational structure of membranes (Chopra et al. 2015, Rohani et al. 2015, Wolf et al. 2013). In addition, studies demonstrated that MMP-2 and MMP-9 were associated with hair cycle (Hou et al. 2015, 2016, Jarrousse et al. 2001). Previous studies have indicated that various growth factors are expressed in the hair follicle, such as EGF, KGF, VEGF, IGF-1, and TGF- $\beta$ (Danilenko et al. 1996). Among them, VEGF, IGF-1, and KGF stimulated hair growth, whereas EGF and TGF- $\beta$ suppressed hair growth (Guo et al. 1996, Lachgar et al. 1996, Philpott et al. 1994b). Furthermore, researches showed that MMP-2 and MMP-9 can regulate numerous growth factors including VEGF, TGF- $\beta$, TNF- $\alpha$, and IL- $1 \alpha$ which play essential roles in hair growth (Gomes et al. 2012, Poyer et al. 2009).

In the present study, we confirmed that 6-Gingerol induced MMP2 and MMP9 expression, which played an important role in hair cycle progression and hair growth (Ling et al. 2010). MMP2 and MMP9 are typical ECM-degrading enzymes, which were proven to be involved in hair growth by VEGF, IGF-1, and TGF- $\beta$ (Hou et al. 2015). In our study, we found that 6-Gingerol decreased EGF, KGF, VEGF, and IGF-1 concentrations, and increased TGF- $\beta$ concentration.

In conclusion, our findings demonstrated that 6-Gingerol played an important role in regulating hair growth via induction of MMP2 and MMP9 expression, which suggested that 6-Gingerol not only cannot treat hair loss, but can restrain hair growth. Therefore, we suggested that this study might provide insights into the prevention for hair loss.

\section{ACKNOWLEDGMENTS}

This study was supported by funds from the Guangzhou Traditional Chinese Medicine and Integrative projects of 2016 (No: 20162A011017). 


\section{REFERENCES}

BASSINO E, GASPARRI F, GIANNINI V AND MUNARON L. 2015. Paracrine crosstalk between human hair follicle dermal papilla cells and microvascular endothelial cells. Exp Dermatol 24: 388-390.

BAYER-GARNER IB, SANDERSON RD AND SMOLLER BR. 2002. Syndecan-1 is strongly expressed in the anagen hair follicle outer root sheath and in the dermal papilla but expression diminishes with involution of the hair follicle. Am J Dermatopathol 24: 484-489.

BRAKEBUSCH C ET AL. 2000. Skin and hair follicle integrity is crucially dependent on beta 1 integrin expression on keratinocytes. EMBO J 19: 3990-4003.

CHAKRABORTY D, MUKHERJEE A, SIKDAR S, PAUL A, GHOSH S AND KHUDA-BUKHSH AR. 2012. [6]-Gingerol isolated from ginger attenuates sodium arsenite induced oxidative stress and plays a corrective role in improving insulin signaling in mice. Toxicol Lett 210: 34-43.

CHEN P, CESCON M AND BONALDO P. 2015. Lack of Collagen VI Promotes Wound-Induced Hair Growth. J Invest Dermatol 135: 2358-2367.

CHOI HI ET AL. 2011. Hair greying is associated with active hair growth. Br J Dermatol 165: 1183-1189.

CHOPRA K, BAVEJA A AND KUHAD A. 2015. MMPs: a novel drug target for schizophrenia. Expert Opin Ther Targets 19: 77-85.

CURTIS A, CALABRO K, GALARNEAU JR, BIGIO IJ AND KRUCKER T. 2011. Temporal variations of skin pigmentation in $\mathrm{C} 57 \mathrm{BL} / 6$ mice affect optical bioluminescence quantitation. Mol Imaging Biol 13: 11141123.

DANILENKO DM, RING BD AND PIERCE GF. 1996. Growth factors and cytokines in hair follicle development and cycling: recent insights from animal models and the potentials for clinical therapy. Mol Med Today 2: 460-467.

FUJIE T, KATOH S, OURA H, URANO Y AND ARASE S. 2001. The chemotactic effect of a dermal papilla cellderived factor on outer root sheath cells. J Dermatol Sci 25: 206-212.

FULWIDER WK, GRANDIN T, GARRICK DJ, ENGLE TE, LAMM WD, DALSTED NL AND ROLLIN BE. 2007. Influence of free-stall base on tarsal joint lesions and hygiene in dairy cows. J Dairy Sci 90: 3559-3566.

GEYFMAN M, PLIKUS MV, TREFFEISEN E, ANDERSEN B AND PAUS R. 2015. Resting no more: re-defining telogen, the maintenance stage of the hair growth cycle. Biol Rev Camb Philos Soc 90: 1179-1196.

GOMES LR, TERRA LF, WAILEMANN RA, LABRIOLA L AND SOGAYAR MC. 2012. TGF-betal modulates the homeostasis between MMPs and MMP inhibitors through p38 MAPK and ERK1/2 in highly invasive breast cancer cells. BMC Cancer 12: 26.

GRINZI P. 2011. Hair and nails. Aust Fam Physician 40: 476484.

GUO L, DEGENSTEIN LAND FUCHS E. 1996. Keratinocyte growth factor is required for hair development but not for wound healing. Genes Dev 10: 165-175.

HARKEY MR. 1993. Anatomy and physiology of hair. Forensic Sci Int 63: 9-18.

HOU C, MIAO Y, WANG J, WANG X, CHEN CY AND HU ZQ. 2015. Collagenase IV plays an important role in regulating hair cycle by inducing VEGF, IGF-1, and TGFbeta expression. Drug Des Devel Ther 9: 5373-5383.

HOU C, MIAO Y, WANG X, CHEN C, LIN B AND HU Z. 2016. Expression of matrix metalloproteinases and tissue inhibitor of matrix metalloproteinases in the hair cycle. Exp Ther Med 12: 231-237.

ITAMI S, KURATA S AND TAKAYASU S. 1995. Androgen induction of follicular epithelial cell growth is mediated via insulin-like growth factor-I from dermal papilla cells. Biochem Biophys Res Commun 212: 988-994.

JARROUSSE F, BOISNIC S, BRANCHET MC, BERANGER JY, GODEAU G, BRETON L, BERNARD BA AND MAHE YF. 2001. Identification of clustered cells in human hair follicle responsible for MMP-9 gelatinolytic activity: consequences for the regulation of hair growth. Int J Dermatol 40: 385-392.

JINDO T, TSUBOI R, IMAI R, TAKAMORI K, RUBIN JS AND OGAWA H. 1995. The effect of hepatocyte growth factor/scatter factor on human hair follicle growth. J Dermatol Sci 10: 229-232.

JUNG MK ET AL. 2015. Hair-growth stimulation by conditioned medium from vitamin D3-activated preadipocytes in C57BL/6 mice. Life Sci 128: 39-46.

KIRATIPAIBOON C, TENGAMNUAY P AND CHANVORACHOTE P. 2016. Ciprofloxacin Improves the Stemness of Human Dermal Papilla Cells. Stem Cells Int 2016: 5831276.

LACHGAR S, MOUKADIRI H, JONCA F, CHARVERON M, BOUHADDIOUI N, GALL Y, BONAFE JL AND PLOUET J. 1996. Vascular endothelial growth factor is an autocrine growth factor for hair dermal papilla cells. J Invest Dermatol 106: 17-23.

LAY K, KUME T AND FUCHS E. 2016. FOXC1 maintains the hair follicle stem cell niche and governs stem cell quiescence to preserve long-term tissue-regenerating potential. Proc Natl Acad Sci USA 113: E1506-1515.

LI H, CUI D, TONG X, MA N, GAO Y, CUI X, LU L, WANG D AND LIANG Y. 2002. The role of matrix metalloproteinases in extracellular matrix remodelling in chronic obstructive pulmonary disease rat models. Zhonghua Nei Ke Za Zhi 41: 393-398. 
LING H, YANG H, TAN SH, CHUI WK AND CHEW EH. 2010. 6-Shogaol, an active constituent of ginger, inhibits breast cancer cell invasion by reducing matrix metalloproteinase-9 expression via blockade of nuclear factor-kB activation. Br J Pharmacol 161: 1763-1777.

MIAO Y, SUN Y, WANG W, DU B, XIAO SE, HU Y AND HU Z. 2013a. 6-Gingerol inhibits hair shaft growth in cultured human hair follicles and modulates hair growth in mice. PLoS ONE 8: e57226.

MIAO Y, SUN YB, WANG WJ, ZHANG ZD, JIANG JD, LI ZH AND HU ZQ. 2013b. Inhibition effect of 6-Gingerol on hair growth. Zhonghua Zheng Xing Wai Ke Za Zhi 29: 448-452.

OH JW ET AL. 2016. A Guide to Studying Human Hair Follicle Cycling in vivo. J Invest Dermatol 136: 34-44.

PARK PJ ET AL. 2012. Hair growth-promoting effect of Aconiti Ciliare Tuber extract mediated by the activation of Wnt/beta-catenin signaling. Life Sci 91: 935-943.

PATEL S, SHARMA V, CHAUHAN NS, THAKUR M AND DIXIT VK. 2015. Hair Growth: Focus on Herbal Therapeutic Agent. Curr Drug Discov Technol 12: 21-42.

PAZYAR N, FEILY A AND KAZEROUNI A. 2012. Green tea in dermatology. Skinmed 10: 352-355.

PHILPOTT MP AND KEALEY T. 1994a. Effects of EGF on the morphology and patterns of DNA synthesis in isolated human hair follicles. J Invest Dermatol 102: 186-191.

PHILPOTT MP, SANDERS DA AND KEALEY T. 1994b. Effects of insulin and insulin-like growth factors on cultured human hair follicles: IGF-I at physiologic concentrations is an important regulator of hair follicle growth in vitro. J Invest Dermatol 102: 857-861.

PINSKI KS. 2014. Patient satisfaction following the use of a hair fiber filler product to temporarily increase the thickness and fullness of thinning hair. Skinmed 12: 278281.

PLIKUS MV AND CHUONG CM. 2014. Macroenvironmental regulation of hair cycling and collective regenerative behavior. Cold Spring Harb Perspect Med 4(1): a015198.

POYER F, COQUEREL B, PEGAHI R, CAZIN L, NORRIS V, VANNIER JP AND LAMACZ M. 2009. Secretion of MMP-2 and MMP-9 induced by VEGF autocrine loop correlates with clinical features in childhood acute lymphoblastic leukemia. Leuk Res 33: 407-417.

PULKOSKI-GROSS AE. 2015. Historical perspective of matrix metalloproteases. Front Biosci (Schol Ed) 7: 125149.
ROHANI MG AND PARKS WC. 2015. Matrix remodeling by MMPs during wound repair. Matrix Biol 44-46: 113-121.

RUDKOUSKAYA A, WELCH I AND DAGNINO L. 2014. ILK modulates epithelial polarity and matrix formation in hair follicles. Mol Biol Cell 25: 620-632.

SAMPATH C, ZHU Y, SANG S AND AHMEDNA M. 2016. Bioactive compounds isolated from apple, tea, and ginger protect against dicarbonyl induced stress in cultured human retinal epithelial cells. Phytomedicine 23: 200-213.

SHIMAOKA S, TSUBOI R, JINDO T, IMAI R, TAKAMORI K, RUBIN JS AND OGAWA H. 1995. Hepatocyte growth factor/scatter factor expressed in follicular papilla cells stimulates human hair growth in vitro. J Cell Physiol 165: 333-338.

STAMENKOVIC I. 2003. Extracellular matrix remodelling: the role of matrix metalloproteinases. J Pathol 200: 448464.

TAMIOLAKIS D, PAPADOPOULOS N, ANASTASIADIS P, KARAMANIDIS D, ROMANIDIS K, STELLOS K, KOTINI A, POLIHRONIDIS A AND SIMOPOULOS C. 2001. Expression of laminin, type IV collagen and fibronectin molecules is related to embryonal skin and epidermal appendage morphogenesis. Clin Exp Obstet Gynecol 28: 179-182.

TRUEB RM. 2013. The difficult hair loss patient: a particular challenge. Int J Trichology 5: 110-114.

WERNER S, SMOLA H, LIAO X, LONGAKER MT, KRIEG T, HOFSCHNEIDER PH AND WILLIAMS LT. 1994. The function of KGF in morphogenesis of epithelium and reepithelialization of wounds. Science 266: 819-822.

WOLF K ET AL. 2013. Physical limits of cell migration: control by ECM space and nuclear deformation and tuning by proteolysis and traction force. J Cell Biol 201: 10691084.

WON CH, JEONG YM, KANG S, KOO TS, PARK SH, PARK KY, SUNG YK AND SUNG JH. 2015. Hair-growthpromoting effect of conditioned medium of high integrin alpha6 and low CD 71 (alpha6bri/CD71dim) positive keratinocyte cells. Int J Mol Sci 16: 4379-4391.

ZHU Y, ZHAO Y, WANG P, AHMEDNA M AND SANG S. 2015. Bioactive ginger constituents alleviate protein glycation by trapping methylglyoxal. Chem Res Toxicol 28: 1842-1849. 